\title{
LA PROTECCIÓN DE LOS NIÑOS MIGRANTES, EL INTERÉS SUPERIOR Y SU RELACIÓN CON LA TRATA DE PERSONAS EN MÉXICO
}

\author{
Yesenia Guadalupe Crespo Gómez ${ }^{1}$ \\ Ana Rosa Rodriguez Luna ${ }^{2}$
}

\begin{abstract}
Resumen
Debido a la ubicación geográfica en que se ubica México, se considera un país de tránsito y destino para la migración ilegal, en donde se ha detectado que dentro de los grupos que se adentran en el territorio nacional, se encuentran niños, niñas y adolescentes solos o acompañados y que, con independencia de su género, constituyen parte del sector vulnerable de la población debido a su minoría de edad, estatus en el país, así como a las condiciones inherentes a la marginación en que se encuentran, situándolas como víctimas potenciales del delito de trata de personas. Por lo que a través de un estudio holístico y sistemático de la normatividad vigente, de la jurisprudencia y la doctrina, correlacionado con las estadísticas emitidas por el Fondo de las Naciones Unidas para la Infancia, así como a las emitidas por la Comisión Nacional de los Derechos Humanos, y otros organismos nacionales podemos afirmar que es un problema vigente y aún pendiente en la agenda pública del país en donde se concreten los medios que permitan garantizar de forma efectiva sus derechos.
\end{abstract}

Palabras Clave: Niños migrantes, principio de interés superior del niño, derechos humanos, trata de personas, y grupos vulnerables.

\section{INTRODUCCIÓN}

El sistema jurídico mexicano tiene sus cimientos en el respeto irrestricto a los derechos humanos, con independencia de la procedencia de la persona o estatus migratorio, una vez que se encuentran en territorio nacional, es obligación del Estado mexicano su protección; si bien es cierto, hay una serie de requisitos que para la migración legal se prevén y deben cumplirse, también lo es, que garantizar los derechos de los nacionales, no es tarea fácil y menos tratándose de migrantes ilegales, debido a que en la mayoría de los casos las autoridades desconocen de su

\footnotetext{
${ }^{1}$ Profesor investigador titular A, tiempo completo, miembro del Sistema Nacional de Investigadores. Perfil Deseable PRODEP y miembro del núcleo académico básico del posgrado integrado de Estudios Jurídicos del Programa Nacional de Posgrados de Calidad-CONACYT. Universidad Juárez Autónoma de Tabasco. México. E-mail: yesecres@hotmail.com

${ }^{2}$ Profesor invetsigador de la Universidad Juárez Autónoma de Tabasco, miembro del Sistema Nacional de Investigadores y perfil deseble PRODEP. Universidad Juárez Autónoma de Tabasco. México. E-mail: rodlar2003@hotmail.com
} 
tránsito por el país y solo se percatan o tienen registros de esta situación cuando son detenidos por las autoridades migratorias o cuando han sido víctimas de algún hecho delictuoso o incluso participe en alguno.

Existe todo un andamiaje normativo que regula la calidad migratoria de las personas y también los supuestos en los cuales al contravenirse el estatus legal de su estancia en el país se debe proceder y, en especial los lineamientos para la atención de los niños migrantes solos o acompañados que, por razones económicas, de marginación, pobreza, inseguridad, falta de trabajo y educación que viven día a día en sus países de origen, buscan emigrar en aras de una mejor condición de vida.

Es menester aclarar que, en este trabajo nuestro principal objetivo, será analizar la migración ilegal de los menores solos o acompañados, debido a que representa un foco rojo para los Estados por los riesgos que conlleva; es decir, las constantes violaciones a derechos humanos que en el camino de tránsito a su lugar de destino llegan a afrontar. No solo se debe enunciar, la discriminación, marginación, hambre o malos tratos, sino que debemos dirigir nuestra atención a uno de los delitos más graves que enfrentan los Estados y que trasgreden fronteras: la trata de personas, una modalidad de la esclavitud que puede tener diferentes fines, pero que cualquiera de ellos representa un menoscabo a la dignidad de la persona y por supuesto tratándose de niños, una afrenta a la humanidad.

En México el sistema de justicia penal, tiene un diseño de corte garantista, en el cual se contemplan los compromisos internacionales contraídos en materia de derechos humanos y por ende, su protección a los menores de edad sea cual sea su condición o calidad migratoria aun cuando es ilegal, porque al ser niños poco o nada importa este estatus, sino priorizar la obligación de los Estados para crear un ambiente seguro en el cual se puedan desarrollar, porque su sola condición de minoría los sitúa dentro de los grupos que consideramos vulnerables; lo que llega a propiciar que sean víctimas de los peores delitos, como la esclavitud, el servilismo, el tráfico de órganos, la prostitución forzada, el trabajo forzado, la mendicidad y la pornografía infantil, todos ellos considerados como delitos en la dentro Ley general para prevenir, sancionar y erradicar los delitos en materia de trata de personas y para la protección y asistencia a las víctimas de estos delitos (2012).

\section{Infancia y migración en México}


La infancia definida por el Fondo de las Naciones Unidas (1946) es la época en la que los niños y niñas tienen que estar en la escuela y en los lugares de recreo, crecer fuertes y seguros de sí mismos y recibir el amor y el estímulo de sus familias y de una comunidad amplia de adultos. Donde la condición y calidad de vida que tienen les permite vivir y desarrollarse plenamente y sin miedo. La Organización de las Naciones Unidas, a través de la UNICEF y otras instituciones, buscan generar las condiciones necesarias para que los niños y niñas de cualquier parte del mundo, puedan crecer en igualdad de circunstancias y desarrollarse plenamente en uso, goce y disfrute de sus derechos humanos. Sin embargo es un ideal que en la realidad no se ha concretado, pues las condiciones que cada país presenta desde su geografía, cultura, forma de gobierno, política, economía y justicia difieren unos de otros e inciden de forma positiva o negativa respecto de la calidad de vida de sus habitantes.

Cuando se habla del Estado mexicano se considera como un régimen político o como un Estado de derecho democrático, pero no solo desde la óptica de garantizar la participación ciudadana, sino por el compromiso de hacer valer los derechos humanos y su defensa (Correas, 2003: p. 46), incluida su progresividad.

Lo que es una realidad es que con independencia de la región o del país que hablemos, en algunos casos tenemos problemas y objetivos comunes que se deben resolver; por lo menos en América, en la actualidad la migración sigue siendo un trabajo pendiente en la agenda de todos los países, puesto que no basta con solo regularla y enunciar políticas dirigidas a la materia, sino de concretar los fines para los cuales fueron creadas, y más tratándose de la migración ilegal, que es un claro reflejo de la necesidad de búsqueda de mejores satisfactores y condiciones de vida para las personas que emigran.

Por su situación geográfica México es considerado un país no solo de destino, sino en la mayoría de casos de tránsito hacia el norte del continente, lo que ha propiciado un aumento considerable en las últimas décadas del flujo migratorio; en particular del fenómeno de menores migrantes que transitan solos al escapar de la violencia, abusos y falta de oportunidades que se vive en su país, o bien, para reunirse con familiares que migraron con anterioridad a los cuales pretenden alcanzar, desafiando los peligros que conlleva atravesar territorios desconocidos y muchas veces sin recursos económicos suficientes de forma ilegal, afrontando todo tipo de riesgos, desde ser víctimas de grupos delincuenciales quienes los reclutan para enlistarlos en sus filas o para explotarlos de todas las maneras posibles; pero aun y con estos riesgos documentados 
(UNICEF, 2017), es un hecho que la migración sigue incrementando y que las mujeres, niños, niñas y adolescentes son las víctimas que más sufren el delito de trata de personas.

El número de casos de niños, niñas y adolescentes extranjeros que migraban sin la compañía de un adulto y fueron detectados por autoridades migratorias mexicanas aumentó un $333 \%$ de 2013 a 2015, es decir de 5,596 ascendió a 18,650 casos (UNICEF, 2017), por lo que esta problemática requiere toda la atención de las autoridades mexicanas y de los organismos internacionales, pues es una realidad que demuestra un incremento y una inminente necesidad de mejorar o reforzar las políticas en la materia.

El 97\% de los niños migrantes en 2015 provenía de Honduras (27.4\%), Guatemala (49.6\%) y El Salvador (20.5\%). La mayoría de ellos eran adolescentes de entre 12 y 17 años. En el mismo año hubo más de 11 mil eventos de repatriación de niñas, niños y adolescentes migrantes mexicanos desde Estados Unidos. De ellos el 84\% $(9,841)$ viajaban sin la compañía de un adulto (Ídem).

Las estadísticas publicadas por UNICEF en mayo de 2017, sostienen que los niños son a menudo detenidos como un paso hacia la deportación. Y que en el año 2016, más del $85 \%$ de los niños y adolescentes migrantes no acompañados de América Central que fueron detenidos en México fueron devueltos a sus países.

El regreso de los niños a sus países de origen puede ser coherente con sus derechos, cuando una determinación de intereses mejores establece que esto proporciona una solución duradera para un niño en lo particular y no implica riesgo de persecución o daño.

En el año 2014, se detectaron más de 63.000 víctimas de trata en 106 países y territorios. Los niños siguen siendo el segundo grupo de víctimas del delito de trata más grande a nivel mundial después de las mujeres, con la particularidad de que en los países de África subsahariana, Centroamérica y el Caribe, se reflejan mucho más víctimas infantiles que víctimas adultas: el 64\% en África subsahariana y el 62\% en América Central y el Caribe, cifras registradas tan solo en el 2014; en donde las niñas siguen siendo el grupo más grande de personas víctimas de trata, en comparación con los varones (UNICEF, 2017).

Se considera que hay múltiples factores que propician el aumento del flujo migratorio internacional, dentro de los que se puede enunciar: a) el envejecimiento y bajas tasas de fecundidad en países desarrollados, b) oferta de empleos y mejor remuneración que en sus países de origen y, c) mejores condiciones de servicios públicos (UNICEF, 2017). Pero con 
independencia de la percepción que el migrante tiene respecto de la promesa de una mejor calidad de vida, los embates que enfrenta pueden ser mucho mayores al sueño que se crea.

Ahora bien, no todos los niños que solicitan asilo tienen protección para refugiados, por ejemplo, de 1.637 niños no acompañados que llegaron a los Estados Unidos de América Central entre julio y octubre de 2014, sólo a 179 se les concedió permiso para permanecer. Existen normas muy diferentes entre países, ya que los Estados que ratificaron la Convención de 1951 pueden ejercer facultades discrecionales para manejar los procedimientos de asilo y determinar la condición de refugiado. Un niño de un determinado país de origen puede tener buenas posibilidades de ser aceptado como refugiado en un país, pero tiene pocas perspectivas en otro (UNICEF, 2017).

El fenómeno de la migración refleja la ineficacia de los Estados de proveer a sus nacionales de los satisfactores necesarios para lograr una vida armoniosa y plena. Los menores sufren no solo en los casos en que deciden emigrar, sino al ser parte de una familia que afronta la desintegración, afectando su normal desarrollo físico y emocional; se sostiene que las pérdidas de referentes o guías (padre, madre, abuelos o familiares en general) en los niños tiene un efecto psicosocial negativo que puede reflejar sentimientos de abandono y vulnerabilidad, pérdida de autoestima e incluso de la infancia misma, al tener que adquirir obligaciones propias de los adultos siendo autosuficientes para sí mismos, y en algunos casos proveedores de satisfactores para otros miembros de su entorno familiar.

\section{Panorama de los derechos humanos en México y su impacto en el sistema jurídico mexicano.}

El 10 de junio de 2011 (Diario Oficial de la Federación, 2011), significó para el sistema jurídico mexicano un avance en materia de derechos humanos, al insertar en la carta magna de forma textual en el capítulo I, la denominación de los derechos humanos y sus garantías, haciendo hincapié en el texto constitucional, la obligatoriedad de su cumplimiento y la protección por el Estado mexicano para su consagración.

También se debe tener dentro presente que dentro de estas reformas de orden constitucional en materia de derechos humanos, el 12 de octubre del mismo año, se reformó el artículo 4o. constitucional para incorporar el principio del interés superior de la niñez, 
incluyéndose a partir de la citada reforma en las políticas públicas del gobierno mexicano (Pérez Fuentes, 2014).

Es por ello, que invocar los derechos humanos que nos asisten como persona, es parte de la realidad jurídica mexicana y no sólo un ideal plasmado en lo que en algún tiempo se consideró letra muerta y una máxima lejana de concretar. Es una transformación normativa que ha impactado a todo el sistema jurídico, así como la forma de procurar e impartir justicia, pero que también se ha extendido a todos los demás ámbitos de la vida pública en el país, como la salud, la educación, la vivienda, la seguridad social, el trabajo, la migración, entre otros; entendiéndose en este sentido que, en cualquier materia la prevalencia de los derechos fundamentales es una constante.

Tampoco debemos pasar por alto que en junio de 2008 (Carbonell, 2012), se dio otra reforma que aunque no es especifica en materia de derechos humanos, si trae implícita su aplicación para alcanzar la concreción del debido proceso en materia penal, y la transición de un sistema mixto con tendencia inquisitiva, a un sistema mixto de corte acusatorio; esto sin lugar a dudas debido a la necesidad de garantizar que las partes involucradas en el proceso, gocen de los derechos y principios contenidos en la constitución y los tratados internacionales aplicables en la materia y que pueda garantizarse el irrestricto respeto a los derechos humanos de los involucrados y el acceso eficaz a la justicia sin distinción alguna, y privilegiando las circunstancias especiales que pudieran surgir, como la migración ilegal y la situación de vulnerabilidad que afrontan los niños en tal condición.

Otro aspecto importante de resaltar, es que la reforma en materia de derechos humanos, impactó a todo el Estado, sus instituciones, al derecho en general, pues no hay una sola área en la cual, no se tenga la obligación de su observancia y cumplimiento, tal y como lo sostiene la Suprema Corte de Justicia en la jurisprudencia cuyo rubro se denomina Derechos humanos. Obligación de protegerlos en términos del artículo $1^{o}$, párrafo tercero, de la Constitución Politica de los Estados Unidos Mexicanos, (Semanario Judicial de la Federación, 2015).

La jurisprudencia en materia constitucional emitida por la Suprema Corte de Justicia de la Nación refiere que para determinar el contenido y alcance de los derechos humanos, debe acudirse a ambas fuentes (nacional e internacional), favoreciendo a las personas la protección más amplia. En otras palabras, debemos entender que entre las normas de derechos humanos contenidas en los tratados internacionales y en la Constitución de nuestro país, no existe una relación de jerarquía; es decir, se encuentran al mismo nivel, pues ambas conforman el catálogo 
de derechos humanos válidos y obligatorios para nuestro Estado y funcionan como parámetro de regularidad constitucional; o bien, como otro medio más de control de constitucionalidad.

Vale destacar que la tendencia a unificar el derecho en aras de privilegiar en la norma los derechos humanos, es una constante; dado que se está gestando paulatinamente un complemento entre el derecho interno e internacional (Cafferata, 2000), que se vislumbra no sólo en el continente americano, sino en el sistema universal de derechos humanos (Herrerías, 2012) y que tanta falta hace en todas partes incluido México, porque la norma por sí sola no es suficiente, sino se requiere de voluntad y compromiso de los Estados y también de la sociedad.

Tan es así que los criterios, lineamientos y guías tomados en consideración en los protocolos para la atención de niños, niñas y adolescentes migrantes (2015), se insertan las opiniones consultivas emitidas por la Corte Interamericana de Derechos Humanos: 1) OC-17/02 del 28 de agosto de 2002, sobre la condición jurídica y derechos humanos del niño; 2) OC-18/03 del 17 de septiembre de 2003, acerca de la condición jurídica y derechos de los migrantes indocumentados y; 3) OC-21/14 del 19 de agosto de 2014, sobre los derechos y garantías de niñas y niños en el contexto de la migración y/o en necesidad de protección internacional.

\section{Marco jurídico para la protección de los menores migrantes en México.}

Existen numerosos instrumentos internacionales y nacionales expedidos para la protección de los menores y que son obligatorios para México, pero analizaremos sin ser exhaustivos, los que consideramos son parte de las directrices de las normas vigentes y que contemplan parámetros para la protección plena de los menores migrantes.

\subsection{Marco jurídico internacional}

En la actualidad existe una vasta positivización del derecho tanto internacional como nacional, y es que solo siendo obligatorio su cumplimiento es que se empezó a regular específicamente para los niños, niñas y adolescentes en los diferentes ámbitos de la vida pública y privada de los menores considerando incluso las circunstancias especiales que pudiesen surgir como discapacidad, pertenencia a grupos vulnerables, víctimas de delitos o bien generadores de ellos, así como condiciones de marginación y migración, por citar solo algunos ejemplos. Así como a uniformar conceptos y principios indispensables para interpretar la ley en el sentido más 
favorable para los menores, tratando de cubrir todas sus necesidades básicas y generando las condiciones necesarias para su correcto desarrollo.

También se dio paso a la unificación de criterios en cuanto a la mayoría de edad y respecto de los principios que deben respetárseles en todo momento, así como de la obligación del Estado de garantizar que se cumplan.

\section{A. Declaración Universal de los Derechos Humanos}

Con la Declaración Universal de los Derechos Humanos aprobada en 1948, se asentó en el artículo 1, que todos los hombres nacen libre e iguales en dignidad..., aunque específicamente no hace alusión a niños o menores de edad, es claro que debe considerarse e interpretarse en el contexto más amplio y garantista para todas las personas. La Declaración Universal de los Derechos Humanos, es uno de los documentos más consultados y eje rector de las correspondientes Convenciones sobre derechos humanos, así como la Carta de Derechos, de donde se derivan los derechos fundamentales que hoy en día siguen estudiándose e interpretándose para hacerlos congruentes con la realidad social y con las necesidades de las personas, en aras de fortalecer la fraternidad, la paz y la igualdad entre las personas por enunciar algunos de sus postulados y en contra de toda forma de discriminación, maltrato o explotación.

\section{B. Declaración de los Derechos del Niño}

En Agosto de 1948 se efectuó en Estocolmo un Congreso en donde se redactaron modificaciones a la Declaración de Ginebra (1924), y se emitió la Declaración de la Unión Internacional de Protección a la Infancia, esto debido a la necesidad de regular con mayor amplitud en la materia, estableciéndose específicamente la obligación de proteger al niño por encima de toda consideración de raza, nacionalidad o de creencia, tomando en cuenta su medio familiar y las exigencias de la seguridad social. Pero fue hasta pasada casi una década, que la Asamblea General de las Naciones Unidas consideró que las necesidades de la infancia justificaban una nueva instrumentación independiente, lo que dio nacimiento a la Declaración de los derechos del niño (1959), con la finalidad de que bajo estas pautas los niños pudiesen alcanzar una vida plena; plasmándose en ella, una serie de derechos que todo niño o niña debe gozar, priorizando la protección especial y necesaria en razón de la minoría de edad y en beneficio de su normal desarrollo, bienestar y felicidad. 


\section{Pacto Internacional de Derechos Civiles y Políticos y el Pacto Internacional de Derechos Económicos, Sociales y Culturales}

El 23 de marzo de 1981, México ratifica el Pacto Internacional de Derechos Civiles y Políticos (PIDCP) y el Pacto Internacional de Derechos Económicos, Sociales y Culturales (PIDESC), en lo que atañe a los niños, el artículo 24 del PIDCP, reitera el derecho a la no discriminación en cualquier forma, así como la obligatoriedad de los Estados de establecer las medidas de protección que se requieran, también prevé derechos al nombre, a ser registrado y a la nacionalidad. Y el PIDESC, aunque no se refiere exclusivamente a menores de edad, debe entenderse de forma integradora y sistemática, por lo que todos los derechos consagrados en el protocolo, se entienden también para los menores.

\section{Convención sobre los Derechos del Niño}

En 1990 México ratifica la Convención sobre los derechos del niño, obligándose a crear las condiciones indispensables para que puedan desarrollarse de forma integral, con un nivel de vida adecuado y de crecer en un ambiente armonioso, extendiéndose por supuesto a cualquier niño, niña o adolescente con independencia de su estatus migratorio, raza, religión, idioma, creencia, color, sexo, opinión política o de otra índole, origen étnico o social, posición económica, impedimentos físicos, o cualquier otra condición del niño y que las autoridades deben garantizar priorizando el interés superior del menor. En la observación general No. 14, emitida por el Comité de los derechos del niño (ONU, 2013), se pronuncian respecto de la importancia de la relación del niño con sus padres, estableciendo que en caso de que se vea interrumpida por la migración, deberá preservarse la unidad familiar teniendo en cuenta dicho interés superior, contemplado a su vez en el artículo 4 de la Carta Magna (1917).

En el mismo sentido la Observación No. 6 del Comité en comento (ONU, 2005), señala que los menores de 18 años que se encuentren no acompañados o separados de su familia son destinatarios de la protección y asistencia que el Estado parte debe brindar en cumplimiento de los cánones establecidos en la Convención sobre los derechos del niño, reiterando que no está limitado a los menores que sean nacionales, sino a cualquiera que tenga esta condición de minoría de edad ya sea refugiado, solicitante de asilo, migrante o inmigrante. A decir de la UNICEF (2017), la Convención es el primer tratado internacional de derechos humanos que combina en 
un instrumento único una serie de normas universales relativas a la infancia, y el primero en considerar los derechos de la niñez como una exigencia con fuerza jurídica obligatoria.

\section{E. Convención Americana sobre Derechos Humanos}

En cuanto a la Convención Americana de Derechos Humanos, que rige para los países pertenecientes a la Organización de los Estados Americanos (OEA) y cuya competencia jurisdiccional es la Corte Interamericana de Derechos humanos, instrumento que se ratificó en 1981 y por ende, parte de las leyes supremas de país siguiendo el principio establecido en el artículo 133 de la Constitución Federal.

De acuerdo al artículo 1.1 de la Convención, es deber del Estado mexicano garantizar el respeto de los derechos humanos sin discriminación...y en relación al artículo 19, se impone la obligación de que adopte las medidas necesarias de protección a favor de todo niño, niña y adolescente. Al respecto la Corte Interamericana en la opinión consultiva OC-21/14 de 19 de agosto de 2014, se pronunció sobre los derechos y garantías de los niños, niñas y adolescentes migrantes, solos o acompañados, de tránsito o destino en el país, y su necesidad de protección por parte del Estado; por ello no es una potestad, sino una obligación que las autoridades administrativas como Sistema Nacional DIF, los estatales y municipales, así como de cualquier otra autoridad administrativa o jurisdiccional que tenga facultades para atender los asuntos en materia de menores, cumpla con las medidas necesarias para el pleno disfrute de los derechos que les asisten, sin importar su condición o circunstancia; por tal motivo, incluso si es necesario decretar medidas especiales o más específicas, que las que se decretan para el resto de las personas, el Estado deberá cumplir y hacer cumplir las leyes y políticas destinadas a su efectividad y correcta aplicación.

\subsection{Marco jurídico nacional}

Cuando se analiza el marco jurídico nacional, por cuestiones de jerarquía, se inicia con la Constitución Política de los Estados Unidos Mexicanos; sin embargo, esta ya ha sido analizada en el apartado II, debido a que se relacionó con la reforma de 2011 en materia de derechos humanos y la trasformación que generó en el sistema jurídico mexicano, a nivel normativo e interpretativo, en donde un derecho se analiza de forma sistemática, respetando el principio pro persona y respecto de los niños, niñas y adolescentes, el interés superior del menor y el conjunto 
de derechos humanos que deben respetárseles; en razón del bloque de constitucionalidad surgido o a decir de la Corte, en base a los parámetros de regularidad constitucional.

\section{A. Ley General de los Derechos de las niñas, niños y adolescentes}

Es una Ley de orden público, que se promulgó en el año 2014 y que inspirada en los acuerdos internacionales en materia de derechos humanos de los cuales México es parte, prevé los derechos y garantías que son de aplicación obligatoria en toda la República mexicana para los niños, niñas y adolescentes, como titulares de derechos, de conformidad con los principios de universalidad, interdependencia, indivisibilidad y progresividad propios de los derechos humanos y en consonancia con la reforma constitucional de 2011, específicamente en el artículo 1 y del 4; tratándose de priorizar la aplicación del interés superior del menor, tal y como prevé la tesis emitida por la segunda sala de la Suprema Corte de Justicia donde señala que este principio se erige como la consideración primordial que debe atenderse en cualquier caso o circunstancia que les afecte y que obliga al Estado, a las autoridades y a los adultos a actuar en consecuencia para poder garantizar sus derechos.

Por tal motivo, las autoridades federales, de las entidades federativas y municipales, en el ámbito de sus respectivas competencias, adoptarán medidas de protección especial de derechos de niñas, niños y adolescentes que se encuentren en situación de vulnerabilidad por circunstancias específicas de carácter socioeconómico, alimentario, psicológico, físico, discapacidad, identidad cultural, origen étnico o nacional, situación migratoria o apátrida, o bien, relacionadas con aspectos de género, preferencia sexual, creencias religiosas o prácticas culturales, $u$ otros que restrinjan o limiten el ejercicio de sus derechos (Cantoral, 2015).

Dentro de esta Ley, se contempla un apartado especial sobre niños, niñas y adolescentes migrantes y las medidas de protección que las autoridades deben adoptar para garantizar sus derechos, con independencia de su situación: acompañados, no acompañados, separados, nacionales, extranjeros y repatriados, dejando claro que en ningún supuesto la migración irregular de niña, niño o adolescente constituye por sí solo un delito y de igual forma se obliga a que la autoridad tenga una base de datos de los menores que se encuentren en tal situación.

\section{B. Ley de migración y su protocolo}

Promulgada en 2011, considera a la infancia y a la adolescencia migrantes no acompañada o separada, como un perfil de alta vulnerabilidad, tomado en cuanta los flujos 
migratorios actuales y los riesgos que conllevan para los menores. Denomina niña, niño o adolescente migrante no acompañado: "a todo migrante nacional o extranjero niño, niña o adolescente menor de 18 años de edad, que se encuentre en territorio nacional y que no esté acompañado de un familiar consanguíneo o persona que tenga su representación legal".

De igual forma establece dos principios que se traducen en lineamientos bajo los cuales se debe ejercer dicha ley, el total respeto a los derechos humanos y la prevalencia del interés superior del menor, interpretándose de acuerdo a lo establecido por la Corte y abordado con antelación. Y que también se encuentra estipulado en el Protocolo de actuación para quienes imparten justicia en casos que afecten a niños, niñas y adolescentes, emitido por la Suprema Corte de Justicia de la Nación (2012).

Sin embargo hay que acotar que tratándose del principio de interés superior del menor migrante no acompañado, cuando así convenga será documentado provisionalmente como visitante por razones humanitarias, en tanto se determina su situación jurídica migratoria o bien, el retorno asistido. A excepción si ha sido víctima de un delito, deberán priorizarse las acciones a realizar, para que se le repare el daño, reciba el tratamiento médico y psicológico requerido y se le repare de forma integral los daños; porque un derecho humano que también tienen los migrantes con independencia de su estatus migratorio es el acceso a la justicia.

Esta ley tiene a su vez un protocolo para atender a los niños, niñas y adolescentes no acompañados o separados que se encuentren albergados, en donde colabora el Sistema Nacional para el Desarrollo Integral de la Familia (DIF), la Organización internacional para las migraciones (OIM); en cuanto a la atención consular compete a la Secretaria de Relaciones Exteriores. A su vez el Fondo de Naciones Unidas para el Socorro de la Infancia, contribuye en los programas y acciones en colaboración con el gobierno mexicano.

\section{Los menores migrantes y el combate a la trata de personas: un compromiso internacional en materia penal.}

Debido a que el derecho penal y su proceso son parte el derecho público y el Estado posee el ius puniendi, o derecho de castigar; las personas deben contar con las herramientas necesarias para hacerle frente y poder defenderse en igualdad de circunstancias, máxime que tratándose del área penal, el Estado tiene todo el poder coercitivo a su favor para aplicarlo a quien o quienes en caso de contravenir sus disposiciones normativas lo infrinjan; cabe aclarar que no es solo el hecho 
de castigar por castigar, sino que existe por parte del Estado, la obligación de combatir los delitos que afecten la sana convivencia de las personas y evitar que sean victimizados.

Todos los delitos laceran los derechos de las personas y a su vez de la sociedad, pero hay algunos que por su naturaleza son incluso de mayor gravedad e impacto, y que trasgreden tanto en el ámbito nacional como en el internacional, recayendo la necesidad de su combate regulación y unificación normativa a nivel incluso mundial para poder hacerle frente; uno de ellos es la trata de personas, que puede afectar a cualquier individuo, pero se tiene registrado que quienes se encuentran en situación de vulnerabilidad como los niños, niñas y adolescentes, llegan a ser mayormente afectados y si a eso sumamos la condición de migrantes, estamos ante la presencia de una de las victimas más frágiles y expuestas para los grupos delincuenciales en cualquier parte del mundo, por ello se considera un delito trasnacional, instando la Organización de las Naciones Unidas a los países miembros a su prevención, combate y erradicación (Protocolo de Palermo, 2000).

Para comprender la importancia de la unidad internacional para su combate, debemos entender que la trata de personas constituye un delito y un verdadero problema en el tejido social del mundo. Definirla no es tarea fácil, pues aun normativamente hablando no capta todas sus implicaciones. "Se considera la degradación de la condición humana; significa darle a una persona un trato similar al que se le da a una mercancía; es despojar a las personas de sus derechos y someterlas a las más crueles vejaciones y malos tratos" (Ronquillo, 2007: p. 7).

Cuando se refiere a trata de personas, ya no se limita su concepción a mujeres, sino que se amplió y reconoció que los hombres también han sido víctimas de este delito, y peor aún las niñas, niños y adolescentes, quienes son considerados candidatos idóneos por los grupos delictivos debido a su vulnerabilidad, y en este caso hay que dejar en claro que cualquier menor puede ser víctima de este delito, pero tratándose de migrantes, el riesgo que presentan es aún mayor.

La identificación de los niños víctimas de la trata de seres humanos requiere esfuerzos especiales, dada la gravedad de la violación y las necesidades específicas de protección de estos niños. Los trabajadores de primera línea que entran en contacto con niños en movimiento por su situación migratoria -los agentes de policía, los trabajadores sociales y de salud, los profesionales del sistema de asilo, en el caso de México, corresponde al Sistema Nacional DIF, los inspectores del trabajo y los funcionarios consulares- requieren una formación especial y la población en general debe tener conocimiento respecto de este delito y sus consecuencias, debido a que son 
sometidos a toda clase de degradación, tratados como objetos de comercio y despojados de autoestima y dignidad. Se considera el tercer negocio delictivo más lucrativo del mundo, sólo superado por el tráfico de drogas y de armas, y cada año genera ganancias que van de 32,000 a 36,000 millones de dólares aproximadamente, según estimaciones del Foro de Viena para combatir la Trata de Personas, organizado por diversas agencias de las naciones Unidas (Comisión Nacional de los Derechos Humanos, 2013).

El concepto universalmente aceptado sobre trata de personas, surge en el año 2000, mediante la adopción de 147 países de la Convención de las Naciones Unidas contra el Crimen Organizado Trasnacional, surgiendo el Protocolo de las Naciones Unidas para Prevenir, Reprimir y Sancionar la Trata de Personas, Especialmente Mujeres y Niños, conocido como Protocolo de Palermo (ONU, 2017), ratificado por el Estado Mexicano el 03 de febrero del año 2003, en donde se prevé varias modalidades concernientes a la trata de personas, dentro de las que se incluye la prostitución o cualquier otra forma de explotación con fines sexuales, el trabajo forzado, la esclavitud u otras modalidades análogas, así como la servidumbre y la extracción de órganos. Todas actividades sumamente rentables incluso compitiendo con otras actividades ilícitas como el tráfico de drogas y armas, pues se considera que la materia prima, es decir, la persona degradada en la condición de objeto, puede ser reutilizada una y otra vez.

La prostitución es considerada por algunos autores como uno de los oficios más viejos del mundo, e incluso se ha llegado a justificar su existencia; sin embargo se ejercería en menos medida si existieran las condiciones educativas, laborales, económicas y políticas que permitieran a cada persona, desempeñar una actividad lícita y rentable para llevar una vida digna y decorosa; a decir de Malarek (2013), si no hubiera demanda la prostitución no existiría. No es un asunto de sexualidad femenina, lo considera una creación masculina, en donde si los hombres alrededor del mundo no demandaran sexo pagado no habría necesidad de acorralar, quebrantar y someter a millones de mujeres y niñas en esta existencia deshumanizante; añadiríamos incluso a niños y jóvenes quienes también son sometidos, pues no es exclusiva de las mujeres.

Desde la óptica que se estudie, el comercio carnal ha sido parte de la historia de la humanidad, pero someter a las personas y obtener ganancias que exclusivamente benefician a los tratantes a costa de la degradación del ser humano vuelto objeto, o simple mercancía, arrebatándole su preciada libertad y dignidad.

La reforma en materia de derechos humanos de 2011, también impacto en el área penal, en cuanto al delito de trata de personas; se abrogó la Ley para Prevenir y Sancionar la Trata de 
2007, que se publicó en cumplimiento a los compromisos contraídos en el Protocolo de Palermo (cuatro años después de su entrada en vigor), pero que dio paso a la nueva Ley General para Prevenir, Sancionar y Erradicar los Delitos en Materia de Trata de Personas y para la Protección y Asistencia a las Víctimas de estos delitos, de 14 de junio de 2012, la cual incorpora los derechos humanos que deben garantizarse para las víctimas, sus familiares e incluso testigos; aunque algunas disposiciones estaban contenidas en la ley anterior abrogada, se amplió favorablemente el catálogo de protección.

Además debemos tener en cuenta que tratándose de una Ley de naturaleza general su aplicación es obligatoria, tanto para las autoridades federales como para las autoridades locales; es decir, son de competencia concurrente y establecen obligaciones y facultades en cada uno de los niveles de gobierno, lo que unifica su aplicación en todo el país, ha contrario sensu de la Ley Federal antes existente.

De igual forma se creó el Protocolo para el uso de procedimientos y recursos para el rescate, asistencia, atención y protección de víctimas de trata de personas (Secretaria de Gobernación, 2015), que contempla asistencia migratoria, así como una comisión intersecretarial para colaboraciones y coordinación interinstitucional y un grupo técnico para la incorporación de la perspectiva de género en las políticas de atención y protección de las mujeres migrantes, y también se contempla la atención de migrantes en situación de vulnerabilidad donde sin lugar a dudas la atención y directrices que se orienten a los niños, niñas y adolescentes son indispensables para garantizar el acceso al ejercicio de sus derechos humanos.

\section{CONCLUSIONES}

Los derechos de los migrantes, en específico de los niños, niñas y adolescentes solos o acompañados, han tenido una evolución paulatina y lenta en la agenda política mexicana, Sin embargo, es una obligación internacional proteger a los menores de edad que se encuentren en el país, sean nacionales o extranjeros, migrantes legales o ilegales, esa condición en nada afecta ni debe mermar los derechos humanos que posee y que al entrar en el Estado Mexicano, de acuerdo al artículo 1 de la Carta Magna, se deben proteger y garantizar sin distingo alguno; es cierto que determinados derechos estarán limitados o restringidos por su condición de extranjeros, pero hay derechos que bajo ninguna premisa pueden coartarse, como el derecho a la educación, la salud, la asistencia consular, al acceso a la justicia por mencionar algunos. 
El fenómeno de la migración refleja la ineficacia de los Estados de proveer a sus nacionales de los satisfactores necesarios para lograr una vida armoniosa y plena. Los menores sufren no solo en los casos en que deciden emigrar, sino al ser parte de una familia que afronta la desintegración, afectando su normal desarrollo físico y emocional. Los niños que transitan solos, buscan escapar de la violencia, abusos y falta de oportunidades que se vive en su país, o bien, para reunirse con familiares que migraron con anterioridad a los cuales pretenden alcanzar, desafiando los peligros que conlleva atravesar territorios desconocidos y muchas veces sin recursos económicos suficientes de forma ilegal, afrontando todo tipo de riesgos, desde ser víctimas de grupos delincuenciales quienes los reclutan para enlistarlos en sus filas o para explotarlos de todas las maneras posibles; pero aun y con estos peligros, es un hecho que la migración sigue incrementando y que las mujeres, niños, niñas y adolescentes son las víctimas que más sufren el delito de trata de personas y que ha propiciado que incluso tratándose de migrantes, la ley de la materia prevea acciones para su prevención, sanción, combate y erradicación, creando protocolos y directrices aplicables en casos específicos de migrantes pertenecientes a grupos vulnerables como los niños, las niñas y los adolescentes.

\title{
THE PROTECTION OF MIGRANT CHILDREN, THE BEST INTERESTS AND THEIR RELATIONSHIP WITH TRAFFICKING IN PERSONS IN MEXICO
}

\begin{abstract}
Due to the geographical location in which Mexico is located, it is considered a country of transit and destination for illegal migration, where it has been detected that within the groups that go into the national territory, there are children and adolescents alone or accompanied and that, regardless of their gender, constitute part of the vulnerable sector of the population due to their minority, status in the country, as well as the inherent conditions of marginalization in which they find themselves, placing them as potential victims of the crime of trafficking in persons. So through a holistic and systematic study of current regulations, jurisprudence and doctrine, correlated with the statistics issued by the United Nations Children's Fund, as well as those issued by the National Commission of the Human Rights, and other national organizations can affirm that it is a current problem and still pending in the public agenda of the country where the means are concreted that allow to effectively guarantee their rights.
\end{abstract}

Keywords: Migrant children, principle of the child's best interest, human rights, human trafficking, and vulnerable groups.

\section{REFERENCIAS}


Q

UNITED NATIONS CHILDREN (2017) A child is a child, Protecting children on the move from violence, abuse and exploitation. [Consulta: 14 de abril de 2018]. Disponible en: https://data.unicef.org/wpcontent/uploads/2017/05/UNICEF_A_child_is_a child_May_2017_E $\underline{\text { N.pdf }}$

CAFFERATA NORES, JOSÉ I, (2000) Proceso penal y derechos humanos: La influencia de la normativa supranacional sobre derechos humanos de nivel constitucional en el proceso penal argentino, Argentina, Centro de Estudios Legales y Sociales.

CANTORAL DOMÍNGUEZ, KARLA, (2015) El derecho a la identidad del menor: el caso México, Rev. boliv. de derecho, $\mathrm{n}^{\circ}$ 20, ISSN: 2070-8157, [Consulta: 20 de abril de 2018]. Disponible en: http://www.scielo.org.bo/pdf/rbd/n20/n20_a03.pdf

CARBONELL, MIGUEL (2012) Constitución Política de los Estados Unidos Mexicanos, 168 ed., México, Porrúa.

CASTILlO LÓPEZ, JUAN ANTONIO (2006) Justicia de menores en México, El desfase institucional y jurídico, México, Porrúa.

COMISIÓN NACIONAL DE LOS DERECHOS HUMANOS (2013) Diagnóstico sobre la trata de personas en México. [Consulta: 11 de abril de 2018]. Disponible en: http://www.senado.gob.mx/comisiones/trata_personas/docs/Diagnostico_Trata.pdf

CONVENCIÓN DE LAS NACIONES UNIDAS CONTRA LA DELINCUENCIA ORGANIZADA TRASNACIONAL Y SUS PROTOCOLOS”, NACIONES UNIDAS, NUEVA YORK, (2004.) [Consulta: 05 de junio de 2018]. Disponible en: http://www.unodc.org/docments/treaties/UNTOC/Publications/TOC\%20Convention/TOCeboo k-s.pdf. Consúltese también la exposición de motivos del Decreto por el que se expide la "Ley General para Prevenir, Sancionar y Erradicar los Delitos en Materia de Trata de Personas y para la Protección y Asistencia a las Víctimas de estos Delitos; y abroga la Ley para Prevenir y Sancionar la Trata de Personas; y reforma diversas disposiciones de la Ley Federal contra la Delincuencia Organizada; del Código Federal de Procedimientos Penales; del Código Penal 
Q

Federal; de la Ley Orgánica del Poder Judicial de la Federación; de la Ley de la Policía Federal y de la Ley General del Sistema Nacional de Seguridad Pública”, Publicado en el Diario Oficial de

http://www.diputados.gob.mx/LeyesBiblio/proceso/lxi/253 DOF_14jun12.pdf

CORREAS, OSCAR (2003) Acerca de los derechos humanos. Apuntes para un ensayo, México, Ediciones Coyoacán, UNAM.

DIARIO OFICIAL DE LA FEDERACIÓN (2011) Decreto por el que se modifica la denominación del Capítulo I del Título Primero y reforma diversos artículos de la Constitución Política de los Estados Unidos Mexicanos, [Consulta: 05 de junio de 2018]. Disponible en: http://dof.gob.mx/nota_detalle.php?codigo $=5194486 \&$ fecha $=10 / 06 / 2011$

HERRERÍAS CUEVAS, IGNACIO Y RODRÍGUEZ, MARCOS DEL ROSARIO (2012) El control de constitucionalidad y convencionalidad: sentencias que han marcado un nuevo paradigma (2007-2012), México, UBIJUS.

MALAREK, VICTOR (2013) The johns: sex for sale and the men who buy it, citado por CACHO, LYDIA, Esclavas del poder un viaje al corazón de la trata sexual de niñas y mujeres en el mundo, México, Grijalvo, Proceso, Colección momento de México.

SISTEMA NACIONAL PARA EL DESARROLLO INTEGRAL DE LA FAMILIA (2015) Marco Jurídico del Protocolo de atención para niñas, niños y adolescentes migrantes no acompañados o separados que se encuentren albergados, Organización internacional de las migraciones, México-Fondo de seguridad humana, [Consulta: 10 de abril de 2018]. Disponible en:

http://www.dif.gob.mx/diftransparencia/media/Marco\%20jur\%C3\%ADdico\%20del\%20Protoc olo.pdf

OBSERVATORIO NACIONAL CIUDADANO (2014) Estadística sobre la eficiencia en el combate a la trata de personas en México, un ejercicio de acceso a la información 2010-2013, 
México, [Consulta: 14 de abril de 2018]. Disponible en: http://onc.org.mx/wpcontent/uploads/2014/01/Documento-Trata-ONC-.pdf

PÉREZ FUENTES, GISELA (2014) La protección de los niños migrantes en México: una falacia, Barataria, Revista Castellano-Manchega de Ciencias Sociales, No 17, [Consulta: 20 de mayo de 2018]. Disponible en: http://www.redalyc.org/pdf/3221/322132552007.pdf

SECRETARIA DE GOBERNACIÓN (2015) Protocolo para el uso de procedimientos y recursos para el rescate, asistencia, atención y protección de víctimas de trata de personas, [Consulta: 15 de junio de 2018]. Disponible en: https:/www.gob.mx/segob/documentos/protocolo-para-el-uso-de-procedimientos-y-recursospara-el-rescate-asistencia-atencion-y-proteccion-de-victimas-de-trata-de-personas

RONQUILLO, VÍCTOR (2007) Los niños de nadie, trata de personas a ras de asfalto, México, CEIDAS.

TESIS DE JURISPRUDENCIA (2015). Aprobada por la Primera Sala de la Suprema Corte de Justicia de la Nación, en sesión privada de quince de abril de dos mil quince. Esta tesis se publicó el viernes 24 de abril de 2015 a las 09:30 horas en el Semanario Judicial de la Federación. [Consulta: 12 de junio de 2018]. Disponible en: http://200.38.163.178/sjfsist/Paginas/tesis.aspx

UNICEF (2017) Temas de políticas públicas e infancia, [Consulta: 12 de junio de 2018]. Disponible en: https://www.unicef.org/lac/migracion_e infancia.pdf

UNICEF-MÉXICO (2017) La niñez migrante: vidas en tránsito, [Consulta: 12 de junio de 2018]. Disponible en: https://www.unicef.org/mexico/spanish/17043.html

Trabalho recebido em 22 de janeiro de 2019 Aceito em 24 de fevereiro de 2019 